\title{
США ЗАТЯГИВАЮТ ЕВРОПУ В БЛИЖНЕВОСТОЧНЫЕ КОНФЛИКТЫ
}

Аннотация. 13-14 февраля 2019 г. в Варшаве проходила конференция «высокого уровня» по проблемам конфликтов на Ближнем Востоке. Изначально Вашингтон и Варшава задумывали мероприятие как откровенно антииранский форум, но, не получив поддержки ведущих стран Евросоюза, расширили повестку, включив в неё проблему палестино-израильского противостояния и войны в Сирии и Йемене. Результаты конференции показали, что по всему спектру вопросов разногласия между администрацией Трампа и европейцами не только сохраняются, но и углубляются. Особенно после решения американского президента вывести свои войска из Сирии.

Ключевые слова: США, Евросоюз, Сирия, Иран, ядерная программа, Варшавская конференциия.

Благодаря усилиям команды, представлявшей администрацию Дональда Трампа (вицепрезидент Майк Пенс, госсекретарь Майк Помпео, спецпредставитель президента по Ближнему Востоку Джаред Кушнер, а также Рудольф Джулиани, юридический советник Белого дома), антииранская направленность оставалась главной темой варшавского форума. Сразу после своей речи на открытии конференции М. Помпео заявил журналистам следующее: «Невозможно достичь стабильности на Ближнем Востоке без противодействия Ирану. Его злокачественное влияние распространяется на Ливан, Йемен, Сирию и Ирак. Три «Х»- хуситы, Хамас и Хизбалла - представляют реальную угрозу в регионе» ${ }^{1}$.

\section{Конференция, обречённая на неуспех}

Понятно, что данный форум призван продемонстрировать неизменность и последовательность ближневосточной политики администрации Трампа. Один из двух столпов этой политики - мобилизация союзников и партнёров в регионе на противодействие Ирану. Второй базовый принцип - обеспечение безопасности Израиля. Концепция Варшавской конференции, судя по всему, выстроена именно на этих двух столпах. Она призвана стать площадкой для публичного общения представителей Израиля с коллегами из арабских монархий Персидского залива, в частности, Саудовской Аравии. Это дало повод некоторым наблюдателям сравнить данный форум по значимости и охвату участников (свыше 60 государств) с Мадридской мирной конференцией по Ближнему Востоку 1991 г., назвав варшавское мероприятие «вторым после Мадрида». Вряд ли, однако, такое сравнение оправдано, поскольку конференция в Мадриде проводилась в формате коспонсорства США и СССР (её открывали президенты Джордж Буш-старший и Михаил Горбачёв), а нынешнюю варшавскую Россия игнорирует. Другое отличие: повестка и дух Мадрида-1991 предполагали примирение всех конфликтовав-

(С Шумилин Александр Иванович - доктор политических наук, главный научный сотрудник Отдела европейской безопасности, руководитель Центра «Европа - Ближний Восток» ИЕ РАН. Адрес: 125009, Россия, Москва, ул. Моховая 11-3. E-Mail: mideast@mail.ru.

DOI: http://dx.doi.org/10.15211/vestnikieran12019131136

${ }^{1}$ Wintour P., Holmes O. Mike Pence chides US allies at Warsaw summit on Iran. The Guardian, 15.02.2019. URL: https://www.theguardian.com/world/2019/feb/14/us-and-israel-say-confrontation-with-iran-needed-for-peace. 
ших на тот момент сторон в регионе (прежде всего, разумеется, арабов и израильтян), а варшавский форум нацелен на мобилизацию арабских стран и Израиля на противостояние с Ираном, который, понятно, не был на него приглашён. Одной из задач Варшавской конференции была, судя по всему, попытка Вашингтона запустить процесс формирования широкой антииранской коалиции с участием максимально возможного числа стран Европы. Отсюда, надо полагать, и выбор места проведения форума - столица Польши.

С самого начала идея проведения подобного ближневосточного саммита в Европе (он был заявлен на уровне министров иностранных дел) выглядела достаточно рискованной для администрации Трампа. Взять хотя бы тот факт, что за две недели до открытия конференции руководство Евросоюза сделало новый важный шаг в направлении подтверждения своей приверженности сохранить «ядерную сделку» с Ираном (СВПД - Совместный Всеобъемлющий План Действий от 2015 г.), несмотря на выход из неё Соединённых Штатов. Собравшиеся 31 января 2019 г. в Бухаресте главы МИД стран ЕС одобрили учреждённое Францией, Германией и Великобританией агентство, через которое будут осуществляться расчёты за сделки между европейскими и иранскими компаниями, если частные банки, опасаясь штрафных мер США, откажутся их проводить. Целевая компания со штаб-квартирой в Париже будет действовать как посредническое бюро. Так, Иран сможет и дальше поставлять нефть и другие товары в Европу. Оплату за них бюро будет осуществлять напрямую европейским компаниям, которые продают в Иран промышленные товары, медикаменты и продовольствие. При этом целевая компания не в состоянии оградить европейские корпорации от санкций США ${ }^{1}$. Следовательно, она может быть полезной лишь тем фирмам в Европе, которые ориентированы на работу с Ираном и не опасаются ограничений в доступе к американскому рынку.

На этом фоне глава внешнеполитической службы Евросоюза Федерика Могерини, известная своим жёстким оппонированием политике Трампа в отношении Ирана, отказалась принять участие в Варшавской конференции. Понизили уровень своего участия и ведущие страны ЕС, среди них, в частности, Франция и Германия: они направили на ближневосточный форум заместителей глав своих внешнеполитических ведомств. Только Великобритания направила в Варшаву главу Форин-офиса Джереми Ханта, который подчеркнул, что особый интерес его ведомства вызывает проблема Йемена ${ }^{2}$. Это уточнение следует понимать как выражение солидарности Лондона с позицией ЕС по «ядерной сделке» с Ираном.

Из ближневосточных акторов отказались прибыть на конференцию в Варшаву представители Катара, Турции, Ливана и Палестины. Суннитские монархии Персидского залива, напомним, упрекают эти страны в «чрезмерно мягком» отношении к Ирану. Таким образом, из ближневосточных стран в Варшаве были представлены на высоком уровне главным образом надёжные партнёры и союзники США (Израиль представлял премьер-министр Б. Нетаньяху), что лишний раз высвечивало линию раскола даже среди стран, которые Вашингтон считает своими партнёрами (Катар, Турция, Ливан). Примечательно, что лидеры отказавшихся от участия в варшавском форуме России и Турции, а также не приглашённого туда Ирана провели собственный саммит в Сочи, в ходе которого обсуждали варианты развития событий в Сирии ${ }^{3}$.

Другая линия раскола высветилась на конференции уже среди европейских государств: с одобрением отнеслись к американской позиции по основным конфликтным точкам Ближне-

\footnotetext{
${ }^{1}$ Подробнее об американских санкциях против европейских компаний см. Шумилин А.И. Европейский суверенитет: испытание Ираном. Защита государственного суверенитета - опыт Евросоюза и европейских стран. Колл. монография. Отв. ред. В.Б. Белов. М.: ИЕ РАН, изд-во «Весь Мир», 2018. 204 с. С. 27-38.

${ }^{2}$ Ibish H. Warsaw Ministerial Highlights Challenges Facing Anti-Iran Coalition. The Arab Gulf States Institute in Washington, 2019. Feb.14. URL: https://agsiw.org/warsaw-ministerial-highlights-challenges-facing-anti-iran-coalition/. ${ }^{3}$ Встреча с Президентом Ирана Хасаном Рухани и Президентом Турции Реджепом Тайипом Эрдоганом. Президент России. 14 февраля 2019. URL: http://kremlin.ru/events/president/news/59829.
} Научно-аналитический вестник ИЕ РАН, 2019, №1 
го Востока страны Восточной и Центральной Европы, что заметно контрастировало с позициями ведущих стран ЕС из числа западноевропейских государств. Так в интервью компании CNN бывшая сотрудница Госдепа в ранге посла Азита Раджи заявила следующее: «Непонятно, чего американская сторона пытается добиться от Варшавского форума: нарастить противодействие влиянию Тегерана посредством создания евро-американской коалиции или мобилизовать усилия для достижения мирного урегулирования в регионе в том виде, как оно может быть достигнуто сегодня? В любом случае, однако, столь амбициозная повестка обречена на провал, принимая во внимание отсутствие высокопоставленных участников из Западной Европы. А это уже признак слабости в отношениях США с трансатлантическими союзниками» 1 .

Примечательно, что «отчётливой демонстрацией раскола в Западном сообществе по вопросу Ирана» называет варшавский форум Хусейн Ибиш, ведущий аналитик вашингтонского Института арабских государств Персидского залива, который спонсируется в основном ОАЭ (Arab Gulf States Institute in Washington) ${ }^{2}$.

Одним из бенефициаров Варшавской конференции (и, возможно, единственным) можно считать Израиль. В своей речи там премьер-министр Биньямин Нетаньяху назвал «историческим переломным моментом» уже то обстоятельство, что глава израильского правительства совместно с министрами иностранных дел ведущих арабских стран выступает «с необычной твёрдостью, ясностью и единством в отношении общей угрозы иранского режима». По словам Нетаньяху, это означает важное изменение в восприятии того, что именно необходимо для обеспечения безопасности на Ближнем Востоке и какие существуют возможности для сотрудничества между Израилем и арабскими странами ${ }^{3}$.

Важно подчеркнуть, что добиться поддержки своей ближневосточной политики восточно-европейскими странами США смогли во многом за счёт озабоченности элит этих стран так называемой «российской угрозой». Так, накануне конференции по Ближнему Востоку было объявлено о заключении Польшей договора с США на поставку 20 американских высокомобильных ракетно-артиллерийских систем HIMARS на сумму 414 млн долл. Польский президент Анджей Дуда назвал приобретение новых систем усилением оборонной мощи не только его страны, но и всей Восточной Европы ${ }^{4}$ В ответ же госсекретарь М. Помпео заявил, что США «слишком долго держались вдали от этого региона, предоставив России возможность заполнить вакуум» 5 . Заметим при этом, что в Пентагоне опровергают информацию о готовности этого ведомства увеличить до 4000 человек американскую группировку в Польше как о том просит польская сторона ${ }^{6}$.

\section{Буферная зона в Сирии: ставка на европейцев}

Сразу после завершения Варшавской конференции в американской прессе, в частности, в газете The Washington times от 15 февраля 2019 г. $^{7}$ появилась информация о попытках

\footnotetext{
${ }^{1}$ Gaouette N. US Middle East conference expected to zero in on Iran. CNN, 2019. Feb.14. URL: https://edition.cnn. com/2019/02/13/politics/warsaw-mideast-conference-iran/index.html.

${ }_{2}$ Ibish H. Warsaw Ministerial Highlights Challenges Facing Anti-Iran Coalition. The Arab Gulf States Institute in Washington, 2019. Feb.14. URL: https://agsiw.org/warsaw-ministerial-highlights-challenges-facing-anti-iran-coalition/. 3 Кропман В. Израиль хочет создать с арабскими странами альянс против Ирана. DW, 14.02.2019. URL: https://www.dw.com/ru/израиль-хочет-создать-с-арабскими-странами-альянс-против-ирана/а-47518906.

4 Пенс М. Польша купила у США 20 ракетных систем HIMARS. DW, 13.02.2019. URL: https://www.dw.com/ru/ польша-купила-у-сша-20-ракетных-систем-himars/a-47500565.

5 Sieradzka M. Poland, US hold controversial Middle East conference in Warsaw. DW, 14.02.2019. URL: https://www.dw.com/en/poland-us-hold-controversial-middle-east-conference-in-warsaw/a-47512354.

${ }^{6}$ Wroughton L., Plucinska J. U.S. says in talks with Poland on troop increase. The Reuters. February 13, 2019. URL: https://www.reuters.com/article/us-usa-pompeo-poland-idUSKCN1Q21CG.

${ }^{7}$ Rogin J. The U.S. is asking European countries to deploy troops to Syria. The Washington Post. 2019 , February 15.
} Научно-аналитический вестник ИЕ РАН, 2019, №1 
группы конгрессменов и руководства Пентагона убедить европейских коллег в необходимости на-править на северо-восток Сирии контингент военнослужащих из стран Европы для совместного с США создания там буферной зоны, которая обеспечит безопасность курдского населения. По словам сенатора-республиканца Линдси Грэма, если удастся договориться с европейцами, президент США Д. Трамп согласится оставить в этом регионе «некоторые» американские формирования. Выступая на ежегодной Мюнхенской конференции по безопасности, Грэм ссылался на некую «пост-халифатскую стратегию» с целью защитить курдов от оставшихся сил джихадистов и других угроз ${ }^{1}$.

Судя по всему, такого рода стратегию пытаются разработать критики линии Трампа в Сирии из числа конгрессменов, включая и республиканцев, совместно с руководством военного ведомства. По словам Грэма, председатель Объединённого комитета начальников штабов генерал Джозеф Данфорд скоро обратится к лидерам стран Европы с просьбой о выделении сил для создания такой буферной зоны. Пентагон уже работает над этим планом. Идея состоит в том, чтобы страны Европы увеличили свои воинские контингенты на северо-востоке Сирии до 1500 человек, тогда США смогут выделить около 200 военнослужащих. Пока непонятно, будет ли этот проект реализован под эгидой НАТО, но, по имеющимся сведениям, переговоры о выделении воинских контингентов ведутся напрямую с Великобританией, Францией и Германией ${ }^{2}$.

Заметим, что сенатор Линдси Грэм последовательно лоббирует линию на сохранение американского военного присутствия в Сирии и выступает в защиту интересов курдской общины в этой стране. Его взгляды не всегда совпадают с позицией Д. Трампа. Инициатива, о которой говорит Грэм, выглядит как попытка с американской стороны (в данном случае части конгрессменов и руководства Пентагона) найти компромисс с оппонентами Трампа как в Вашингтоне, так и с европейскими политиками, которые выступили с весьма резкой критикой оглашённого Белым домом 19 декабря 2018 г. решения в ближайшее время вывести американские подразделения из Сирии.

Озабоченности европейцев планами Трампа в Сирии можно суммировать так: уход США может стимулировать возрождение группировки «Исламское государство» (ИГ), может привести к массовым убийствам курдов, новым волнам беженцев в Европу и обретению Россией стратегических преимуществ в ближневосточном регионе. Уже 20 декабря правительства Франции, Германии, Великобритании и Дании на уровне министров выразили своё несогласие с планом Трампа. Спустя несколько дней позицию Франции подтвердил и президент Эммануэль Макрон: он выразил «глубокое сожаление в связи с противоречивым решением Дональда Трампа», напомнив, что союзники по определению должны пребывать в состоянии взаимозависимости ${ }^{3}$. И заявил, что французский контингент остаётся в Сирии для оказания поддержки партнёрам международной коалиции на земле - курдам и сирийским повстанцам. Макрон призвал всех не забывать той решающей роли, которую сыграли подразделения курдов и сирийской оппозиции в освобождении северо-восточной части Сирии от террористов ИГ. А глава МИД Дании Андерс Семуэльсон призвал страны ЕС оказать скоординированное воздействие на администрацию Трампа с тем, чтобы добиться изменения её решения по Сирии ${ }^{4}$.

\footnotetext{
URL: https://www.washingtonpost.com/opinions/2019/02/15/us-is-asking-european-countries-deploy-troops-syria/.

${ }^{1}$ Там же.

2 Там же.

${ }^{3}$ Macron dit «regretter très profondément» la décision américaine de se retirer de Syrie. Le Monde. 23.12.2018. URL: https://www.lemonde.fr/international/article/2018/12/23/macron-dit-regretter-tres-profondement-la-decision-americaine-de-se-retirer-de-syrie_5401594_3210.html.

${ }^{4}$ Rettman A. US allies in dismay at Trump's Syria pull-out. EU Observer, 2018. Dec.21. URL: https://euobserver.
} com/foreign/143784. 
Ведущие страны ЕС подтверждают неизменность своего подхода к борьбе с ИГ и сирийской проблеме в целом. Не удивительно, что на этом фоне руководство группировки СДС (Си-рийские демократические силы), объединяющей курдские и светские антиасадовские формирования, призывает именно Францию усилить свою роль в Сирии. Находясь в Париже 22 декабря, сопредседатель СДС Ильхам Ахмед пояснил в своём обращении к правительству Франции, что после вывода американских подразделений у СДС может не хватить сил не только для ведения боевых действий, но даже для удержания в плену тысяч боевиков ИГ. При этом курды вынуждены готовиться к отражению обещанного Эрдоганом наступления на Северный Курдистан (Рожава). На Америку, по его словам, надежды у курдов нет. Повлиять на турецкое руководство, полагает И. Ахмед, могут только его союзники по НАТО, в частности, Франция .

Как бы то ни было, но пока не сам Трамп, а влиятельные центры силы в конгрессе США и Пентагоне прорабатывают с европейской «тройкой» (Германией, Францией и Великобританией) варианты компромисса с целью минимизировать издержки в случае вывода американских войск из Сирии и стабилизировать ситуацию в подконтрольной им части на северо-востоке страны посредством установления там буферной зоны.

Организованная Соединёнными Штатами Варшавская конференция по Ближнему Востоку подтвердила устойчивость линии администрации Трампа на противодействие Ирану, а также на мобилизацию европейских союзников с целью изоляции Исламской республики. Избранный для этого формат международной конференции предполагает максимальную публичность, что может означать попытку Белого дома апеллировать к европейской общественности с целью оказания давления на правительства стран Западной Европы, продолжающих поддерживать и осуществлять договорённости с Ираном по его ядерной программе (СВПД).

Пытаясь навязать Европе свою линию поведения в отношении Ирана, администрация Трампа, по сути, подталкивает европейцев к конфронтации с Исламской республикой не только по ядерной программе Тегерана, но в обозримой перспективе и по всему периметру противостояния США с Ираном - в Ираке, Сирии, Ливане, Йемене и Сирии. Особенно отчётливо просматривается попытка более активного вовлечения европейцев в контексте плана создания буферной зоны в Сирии: там американская сторона предлагает увеличить европейский контингент при десятикратном (с 2000 до 200 военнослужащих) сокращении своего собственного.

\section{Список литературы}

Встреча с Президентом Ирана Хасаном Рухани и Президентом Турции Реджепом Тайипом Эрдоганом. Президент России. 14 февраля 2019. URL: http://kremlin.ru/events/president/ news/59829.

Кропман В. Израиль хочет создать с арабскими странами альянс против Ирана. DW, 14.02.2019. URL: https://www.dw.com/ru/израиль-хочет-создать-с-арабскими-странамиальянс-против-ирана/а-47518906.

Пенс М. Польша купила у США 20 ракетных систем HIMARS. DW, 13.02.2019. URL: https://www.dw.com/ru/польша-купила-у-сша-20-ракетных-систем-himars/a-47500565.

\footnotetext{
${ }^{1}$ Kurds urge France to play bigger role in Syria amid US troop withdrawal. France 24, 21.12.2018. URL: https:// www.france24.com/en/20181221-kurds-france-role-syria-us-trump-troop-withdrawal-USA-Ilham-Ahmed-Riad-Dara.
} Научно-аналитический вестник ИЕ РАН, 2019, №1 


\section{References}

Gaouette N. US Middle East conference expected to zero in on Iran. CNN, 14.02.2019. URL: https://edition.cnn.com/2019/02/13/politics/warsaw-mideast-conference-iran/index.html.

Ibish H. Warsaw Ministerial Highlights Challenges Facing Anti-Iran Coalition. The Arab Gulf States Institute in Washington, 14.02.2019. URL: https://agsiw.org/warsaw-ministerial-highlightschallenges-facing-anti-iran-coalition/.

Hamidi I. Kurds Make «Secret Offer» to Damascus. Asharq Al-awsat, 05.01.2019. URL: https://aawsat.com/english/home/article/1533171/kurds-make-'secret-offer'-damascus.

Kurds urge France to play bigger role in Syria amid US troop withdrawal. France 24, 21.12. 2018. URL: https://www.france24.com/en/20181221-kurds-france-role-syria-us-trump-troop-with drawal-USA-Ilham-Ahmed-Riad-Dara.

Macron dit «regretter très profondément» la décision américaine de se retirer de Syrie. Le Monde. 23.12.2018. URL: https://www.lemonde.fr/international/article/2018/12/23/macron-ditregretter-tres-profondement-la-decision-americaine-de-se-retirer-de-syrie_5401594_3210.html.

Rettman A. US allies in dismay at Trump's Syria pull-out. EU Observer, 21.12.2018. URL: https://euobserver.com/foreign/143784.

Rogin J. The U.S. is asking European countries to deploy troops to Syria. The Washington Post. 15.02.2019. URL: https://www.washingtonpost.com/opinions/2019/02/15/us-is-asking-europeancountries-deploy-troops-syria/.

Sieradzka M. Poland, US hold controversial Middle East conference in Warsaw. DW, 14.02. 2019. URL: https://www.dw.com/en/poland-us-hold-controversial-middle-east-conference-inwarsaw/a-47512354.

Wintour P., Holmes O. Mike Pence chides US allies at Warsaw summit on Iran. The Guardian, 15.02.2019. URL: https://www.theguardian.com/world/2019/feb/14/us-and-israel-say-confrontation-with-iran-needed-for-peace.

Wroughton L., Plucinska J. U.S. says in talks with Poland on troop increase. The Reuters. 13.02. 2019. URL: https://www.reuters.com/article/us-usa-pompeo-poland-idUSKCN1Q21CG .

\section{The US is enticing Europe into the Middle East conflicts}

Author. Alexander Shumilin, Doctor of Sciences (Politics), Chief Research Associate, European Security Department, Institute of Europe, Russian Academy of Sciences. Address: 11-3, Mokhovaya str., Moscow, Russia, 125009. E-mail: mideast@mail.ru.

Abstract. On February 13-14, 2019, the international conference at the ministerial level took place in Warsaw to envisage issues related to the Middle East conflicts. To note that the conference had been initially conceived by Washington and Warsaw as an openly anti-Iranian forum, but the failed support by the leading European countries pushed them to enlarge the agenda to include the issue of the Israeli-Palestinian confrontation as well as the wars in Syria and Yemen. The conference's results bore out that the divergence on all the spectrum of the issues mentioned above not only remains but is getting wider and deeper in some cases. In particulare, in the aftermath of the American president's decision to pull out the US troops from Syria.

Key words: The USA, European Union, Syria, Iran, the nuclear program, the Warsaw conference.

DOI: http://dx.doi.org/10.15211/vestnikieran12019131136 